\title{
TRANSEXUALIDADE NA ESCOLA: IMPACTOS E DEMANDAS DOS CORPOS MARCADOS PELA SUBVERSÃO
}

\author{
(Transexuality at school: Impacts and Demands of bodies scarred by SUBVERSION)
}

\author{
Leonardo da Cunha Mesquita Cafél \\ (UnB - Universidade de Brasília) \\ Maria Luiza Monteiro Sales Coroa ${ }^{2}$ \\ (UnB - Universidade de Brasília)
}

\section{RESUMO}

A escola é um espaço social em que a diversidade de identidades nem sempre apresenta convivência harmoniosa, especialmente quando grupos minoritários desviantes da hegemonia heteronormativa estão presentes. Estudantes trans carregam as marcas da subversão em seus corpos e sofrem os desdobramentos do discurso transfóbico no ambiente escolar. Sob o aporte teórico-metodológico da ADC (FAIRCLOUGH, 2016; MAGALHÃES et al 2017; RAMALHO e RESENDE, 2016, 2017) e em diálogo com os Estudos de Gênero e Sexualidade (BUTLER, 1993, 2017; LOURO, 2014, 2016; MOITA LOPES, 2008), este artigo busca compreender os impactos da transfobia na vida de alunos/as trans do ensino médio público de Ceilândia/DF, bem como identificar suas demandas e estratégias de enfrentamento através de suas narrativas. Como resultado, notou-se a existência de estratégias de enfrentamento paralelas a ações de resignação e conformidade.

Palavras-chave: Ensino Médio. Heteronormatividade. Identidade Trans. Transfobia.

\begin{abstract}
The school is a social space where identity diversity is not always exposed harmoniously, especially if minority groups, which are deviant from the heteronormative hegemony, are present. Trans students carry the scars of subversion over their bodies, and they suffer the outspread of the transphobic discourse in the school setting. Adopting CDA theoretical-methodological approach (FAIRCLOUGH, 2016; MAGALHÃES et al, 2017; RAMALHO and RESENDE, 2016, 2017) and in dialogue with Gender and Sexuality Studies (BUTLER, 1993, 2017; LOURO, 2014, 2016; MOITA LOPES, 2008), this article aims to understand the impacts of transfobia upon trans students' lives in public secondary school from Ceilandia/DF as well as to examine these students' demands and coping strategies through their narratives. As a result, it was noticed the existence of confrontation strategies paralleled with actions resignation and conformity.
\end{abstract}

Keywords: Heteronormativity. Secondary School. Transphobia. Transgender Identity.

\section{RESUMEN}

La escuela es un espacio social en el que la diversidad de identidades no siempre presenta una convivencia armoniosa, especialmente cuando están presentes grupos minoritarios que se desvían de la hegemonía heteronormativa. Los estudiantes trans llevan las marcas de subversión en sus cuerpos y sufren las consecuencias del discurso transfóbico en el entorno escolar. Bajo el apoyo teórico y metodológico de ADC

\footnotetext{
${ }^{1}$ Mestre em Linguística pela Universidade de Brasília. Professor na SEE/DF desde 1997, onde atua com a formação continuada dos/as profissionais da Educação Básica nos eixos transversais e interseccionais de classe, gênero social, raça e sexualidade. leocafe77@gmail.com

${ }^{2}$ Doutora em Linguística pela UNICAMP. Professora da Universidade de Brasília desde 1994, onde atua nas áreas de Semântica e Análise do Discurso. Trabalha com formação inicial e continuada de professores e é autora e organizadora de materiais pedagógicos em vários programas e projetos de formação continuada, entre eles o Programa GESTAR II e o projeto de Alfabetização e Linguagem, da UnB, ligado à Rede Nacional de Formação Continuada de Professores, ambos do MEC. mluizacoroa@gmail.com
} 
(FAIRCLOUGH, 2016; MAGALHÃES et al 2017; RAMALHO y RESENDE, 2016, 2017) y en diálogo con los Estudios de Género y Sexualidad (BUTLER, 1993, 2017; LOURO, 2014, 2016; MOITA LOPES, 2008), este artículo busca comprender los impactos de la transfobia en la vida de los estudiantes trans de secundaria pública en Ceilandia / DF, así como identificar sus demandas y estrategias de afrontamiento a través de sus narrativas. Como resultado, se observó la existencia de estrategias de afrontamiento paralelas a las acciones de renuncia y cumplimiento.

Palabras clave: Escuela Secundaria. Heteronormatividad. Identidad Trans. Transfobia.

Recebido em: julho 2020

Aceito em: julho 2020

DOI: $10.26512 /$ les.v21i1.32396

\section{INTRODUÇÃO}

A escola é, sem dúvida uma das instituições sociais mais plurais de que se tem notícia. Não é difícil notar o quão diverso esse espaço é ao se adentrar por seus corredores como discente ou docente. A multiplicidade característica do ser humano se descortina frente aos olhos de qualquer espectador/a em um ambiente escolar. Gênero, raça, credo, posições políticas e orientações sexuais das mais diferentes podem ser facilmente identificadas. Entretanto, tamanha pluralidade não necessariamente significa respeito. $\mathrm{O}$ grau de harmonia com o qual essas identidades convivem varia de instituição para instituição. Conflitos ocorrem, com frequência, entre os tantos grupos que ali coexistem, trazendo à tona questões que demandam posição crítica não somente de quem está à frente da gestão desses espaços, mas também dos demais sujeitos que ali interagem.

Nesse contexto, alguns grupos, tais como os das pessoas trans, são mais vulneráveis e estão exponencialmente mais propensos a sofrer com a intolerância, discriminação e preconceito. Essas pessoas carregam em seus corpos as marcas da não-conformidade, isto é, não se encaixam na relação binária, na qual a construção de gênero apresenta um aspecto biológico compreendido nos binômios homemlmulher e masculinolfeminino, como legitimado por nossa sociedade. Ao contrário, as pessoas trans ilustram a noção defendida por Bruns e Pinto (2003) de que gênero é uma construção sóciohistórica em que os conceitos de feminino e masculino podem ser plurais e não pré-estabelecidos ou fixos. Nessa perspectiva, alguns trabalhos na área da Sociologia e também da Linguística têm abordado essa temática. Por exemplo, a tese de Doutorado de Lorena Araújo de Oliveira Borges (UnB, 2018), "Meu corpo, minhas regras": representações e identidades de gênero nos discursos de ativistas (trans)feministas", trata das reconfigurações discursivas que ativistas trans têm feito de seus corpos e dos impactos dessa mudança. A presente pesquisa, apesar de também tratar da corporeidade trans, difere daquela por ter seu foco nas demandas de estudantes trans do Ensino Médio, bem como nos impactos que seus corpos desviantes sofrem na escola. 
É importante aqui esclarecer que o binarismo sustenta a crença de que há uma dualidade simples através da qual se pode relacionar o sexo, caráter biológico, ao gênero, caráter psicossocial, de maneira direta, desconsiderando não só a orientação sexual, atração afetivo-sexual que alguém tenha por outrem, mas principalmente a identidade de gênero, que pode ou não concordar com o sexo atribuído no nascimento.

Sendo assim, as pessoas trans são aquelas que melhor podem relatar as dificuldades de estar no contexto escolar e reivindicar suas demandas por reconhecimento. Por estarem situadas no ambiente escolar e por carregarem as marcas da diversidade, essas pessoas são capazes de reportar, através de suas narrativas, como se dá o enfrentamento em relação à problemática da transfobia na escola. Ouvir suas vozes, respeitando o lugar de fala desses sujeitos, é fundamental para que os impactos na existência trans e as demandas desse grupo sejam compreendidas, fato esse que se configura aqui como justificativa para a proposta deste estudo.

O artigo que é aqui proposto tem como pressupostos teóricos aqueles que norteiam a Análise de Discurso Crítica (ADC), por entendermos a importância do discurso não só como forma de manutenção, mas também de mudança social, e que orientam os Estudos de Gênero e Sexualidade e suas implicações em relação às práticas discursivas e sociais presentes no âmbito escolar:

À ADC também interessa o papel do discurso na mudança social, os modos de organização da sociedade em torno de objetivos emancipatórios. Esse foco de atenção insere a ADC em um paradigma interpretativo crítico, pelo qual intenta oferecer suporte cientifico para estudos sobre o papel do discurso na instauração/ manutenção/ superação de problemas sociais (VIEIRA; RESENDE, 2016, p. 77).

Considerando o reconhecimento da existência de um binarismo que desrespeita a existência dos corpos trans e com base no aporte teórico da ADC, foi desenvolvido o presente artigo cujo objetivo geral é compreender os impactos da transfobia na vida escolar de estudantes trans de escolas públicas de Ensino Médio de Ceilândia, Região Administrativa mais populosa do Distrito Federal, que fica a $30 \mathrm{~km}$ de Brasília. O termo impacto é aqui usado para descrever os desdobramentos da situação de violência simbólica (BOURDIEU, 2018), física e/ou emocional na escola.

Estabelecem-se, então, duas perguntas de pesquisa que norteiam este estudo: Que discursos e mecanismos discriminatórios são utilizados pelos diversos sujeitos da escola em relação aos/às estudantes trans? Quais são as demandas e estratégias de enfrentamento adotadas por esses/as estudantes? Para que tais perguntas sejam respondidas, buscou-se ouvir as pessoas que compõem o foco desse estudo: alunos/as trans do Ensino Médio em escolas públicas de Ceilândia. Suas narrativas curtas (AKOPOULOU, 2007) são materiais valiosos para a análise das práticas sociais que levam à exclusão, discriminação e preconceito dentro dos muros da escola em relação à questão trans. 
A pesquisa de campo foi realizada entre agosto e dezembro de 2018 na Região Administrativa IX do Distrito Federal, Ceilândia, em duas das quatro escolas colaboradoras da pesquisa "O DISCURSO LGBTIFÓBICO NA ESCOLA: Impactos sobre os corpos LGBTI+ de estudantes de quatro escolas públicas de Ensino Médio de Ceilândia-Distrito Federal”. As escolas foram selecionadas considerando a representatividade que cada uma tem dentro das comunidades em que se situam: são de fácil acesso; têm bons níveis de aprovação no Exame Nacional do Ensino Médio (ENEM) e no Programa de Avaliação Seriada (PAS) ${ }^{3}$; apresentam projetos de interação com suas comunidades; e, por consequência dos fatores apresentados, têm um grande e variado número de estudantes. Reduziu-se a geração de dados ao número de duas, considerando o propósito do artigo, pois somente nessas duas instituições havia alunos/as trans colaboradores/as voluntários/as.

A aproximação ao campo se deu após reuniões com os gestores das duas escolas e aprovação da pesquisa pela EAPE, Escola de Aperfeiçoamento de Professores, e encaminhamento da GREC, Gerência Regional de Ensino de Ceilândia, no início do segundo semestre de 2018. Vale ressaltar que a pesquisa se deu conforme aprovação do Comitê de Ética em Pesquisa após parecer consubstanciado favorável.

Os/as colaboradores/as envolvidos/as foram ouvidos/as na própria escola em um lugar reservado (biblioteca, sala de orientação ou coordenação), para que tivessem sua imagem e sua integridade física preservadas. Além disso, os encontros ocorreram durante o horário do turno letivo, a fim de que os/as estudantes trans não precisassem se deslocar de casa novamente. Todos/as os/as colaboradores/as foram esclarecidos/as previamente sobre o conteúdo desta pesquisa e assinaram os Termos de Consentimento Livre e Esclarecido (TCLE) permitindo o uso de suas falas.

Ademais, estima-se que situação similar ao que é analisado aqui aconteça, com maior ou menor frequência, em outras escolas de outras regiões do Distrito Federal e do país, sendo necessária e pertinente uma investigação posterior, além de um movimento constante de pesquisas que busquem oportunizar que as vozes trans sejam percebidas e suas demandas atendidas.

O artigo está dividido em quatro seções, além da introdução. Na seção 1, apresentam-se os pilares teóricos com os quais este estudo foi embasado, ou seja, a ADC e os Estudos de Gênero e Sexualidade. A próxima seção traz informações relativas à metodologia, em que a ADC é retomada porque é também método, além de considerações éticas pertinentes. A seção seguinte, discute os dados gerados à luz do embasamento teórico, ilustrando as categorias de análise com excertos. Finalmente, a seção 4 conclui este artigo com considerações finais que retomam suscintamente os

\footnotetext{
${ }^{3}$ O ENEM e o PAS são exames de avaliação usados para o ingresso dos estudantes do sistema de educação brasileiro nas faculdades e universidades públicas e/ou privadas do país. O ENEM é um exame nacional e o PAS é um exame da Universidade de Brasília aplicado ao fim de cada série do Ensino Médio.
} 
aspectos importantes da discussão e sinalizam para a necessidade de outros estudos para aprofundamento da problemática da convivência trans no ambiente escolar.

\section{A Análise do Discurso Crítica e os Estudos de GÊNERo e SeXualidade}

O termo discurso não pode ser destituído de seu caráter social, quer seja porque é parte integrante das práticas sociais às quais os sujeitos se associam, consciente ou inconscientemente, quer seja por produzir efeitos na sociedade em que é concretizado (FAIRCLOUGH, 2016). Pelos discursos, portanto, práticas sociais materializam-se em práticas discursivas; e por estas aquelas são legitimadas ou deslegitimadas.

Consequentemente, para analisar relações sociais de acesso difuso, textos devem ser entendidos como materializações empíricas do próprio discurso, pois eles são "materialidades discursivas dos eventos, decorrentes das práticas sociais, incluindo fala, escrita e imagem" (MAGALHÃES et al., 2017, p. 23). Dessa maneira, os dados gerados durante as entrevistas, grupos focais e observações são textos que, por óbvio, necessitam ter suas informações expandidas, já que eles refletem as próprias práticas sociais:

Essa percepção de texto como parte discursiva empírica de eventos sociais baseia-se numa visão funcionalista da linguagem, que a entende como um recurso de que as pessoas lançam mão em suas vidas diárias para interagir e se relacionar, para representar aspectos do mundo assim como para "ser", para identificar a si e aos outros (VIEIRA; RESENDE, 2016, p. 24).

A Análise de Discurso Crítica justifica-se por entender que o discurso, materializado nos textos orais ou escritos, age "tanto como reprodutor quanto transformador de realidades sociais, compreendendo o sujeito da linguagem a partir de uma perspectiva psicossocial” (MELO, 2012, p. 11). O discurso tem, então, efeitos sociais que devem ser percebidos através do estudo das práticas sociais em que é possível focalizar não só eventos individuais, mas sim "séries de eventos conjunturalmente relacionados na sustentação e transformação de estruturas", dada a conexão existente entre as práticas sociais, estruturas e eventos (MAGALHÃES et al., 2017, p. 91). Dessa maneira, todos os sujeitos estão, sim, suscetíveis a serem moldados ideologicamente através da linguagem, mas também podem ativar transformações nas suas próprias práticas discursivas em um processo dialógico e dialético de conformação elou resistência no qual o discurso age como modo de ação, "uma forma em que as pessoas podem agir sobre o mundo e especialmente sobre os outros, como também um modo de representação" (FAIRCLOUGH, 2016, p. 94-95).

Portanto, linguagem e ideologia são dois conceitos cruciais para o desenvolvimento destas análises. Entende-se linguagem por todas as semioses discursivas, linguísticas ou não, que atribuem 
aos sujeitos a capacidade de se comunicar. Mais que comunicar, lembrando Gnerre (1998), capacidade de persuadir, uma vez que ninguém fala à toa, falamos para sermos "ouvidos", respeitados ou exercermos influência sobre os ambientes em que estamos situados. Logo, a linguagem assume um caráter não só comunicativo, mecanicamente falando, mas de instância capaz de legitimar o que uns falam em relação aos outros, principalmente quando os/as envolvidos/as se encontram em contextos propícios à dominação, ao preconceito ou à deslegitimação. Portanto, os discursos que se legitimam na escola, sobrepondo-se aos corpos trans e suas vivências escolares, interessam muito ao propósito destas análises, pois se entende aqui a força que a linguagem tem para anular ou privilegiar um corpo em detrimento a outro.

Tamanha legitimidade discursiva não se realiza arbitrariamente e pode ser identificada nas vozes de determinados sujeitos, que representam uma hegemonia do que pode ou não ser concebido como verdade. Emerge, consequentemente, a ideologia dominante presente nas práticas discursivas desses sujeitos. Entende-se ideologia aqui como significações da realidade cuja construção acontece discursivamente, contribuindo "para a produção, reprodução ou transformação das relações de poder" (FAIRCLOUGH, 2016, p. 122), o que acontece repetidamente, uma vez que "em todas as sociedades, a produção e a troca de formas simbólicas - expressões linguísticas, gestos, ações, obras de arte, etc. - é, e sempre tem sido, uma característica onipresente da vida social" (THOMPSON, 2011, p. 9).

Dessa maneira, juntas, linguagem e ideologia caminham na forma de práticas discursivas, naturalizando determinados discursos que se concretizam como práticas sociais. Essas práticas sociais deslegitimam os corpos que subvertem a arbitrariedade da norma compulsória e heteronormativa, que pode estabelecer tabus acerca do que pode ou não ser concebido como existência dentro do ambiente escolar. Sobre como tais práticas são estabelecidas na rotina escolar, uma significativa reflexão sobre a vigilância daquilo que a escola entende como corpos normais é trazida por Louro $(2014$, p. 85) aqui:

Como já observamos, a vigilância e a censura da sexualidade orientam-se, fundamentalmente, pelo alcance da "normalidade" (normalidade essa representada pelo par heterossexual, no qual a identidade masculina e a identidade feminina se ajustam às representações hegemônicas de cada gênero).

No entanto, como a própria autora afirma, os sujeitos que interagem no ambiente acadêmico (gestores/as professores/as e demais estudantes) acreditam que uma preocupação mais aberta a respeito da sexualidade não seja necessária, reforçando a ideia da neutralidade do discurso escolar ou a noção de que a instituição seja apenas o local da aprendizagem, como se pudéssemos separar cognição de corpo. Essa visão de aparente neutralidade, além de simplista, é parcial e mascara os discursos recorrentes de preconceito enfrentados por estudantes LGBTI+, em especial, pessoas trans, como no estudo aqui proposto, pois tenta mostrar que as concepções de gênero e sexualidade que 
circulam socialmente não são reproduzidas na instituição. Todavia, tais concepções (de gênero e de sexualidade) não só são repassadas, mas também produzidas, pois a sexualidade faz parte dos sujeitos e não pode ser despida ou desligada ao se adentrar pelos portões escolares, como se percebe nas palavras de Moita Lopes (2008, p. 126-127):

Esse apagamento do corpo não quer dizer, entretanto, que a escola não produza identidades corporificadas. Ao contrário, embora os/as professores/as estejam apenas começando a perceber a relevância dos discursos escolares na construção da vida social, a escola é uma das agências principais de (re)produção e organização das identidades sociais de forma generificada, sexualizada e racializada.

Assim, há de se ter em mente que o silêncio da escola só é quebrado quando a materialização dos corpos que fogem à normalidade se efetiva. Nesse processo de busca por legitimação, os corpos que carregam marcas mais aparentes, a exemplo dos corpos trans, são sempre os mais vulneráveis e suscetíveis à violência ( simbólica $^{4}$, moral, emocional e física), pois abalam as estruturas hegemônicas presentes nos discursos.

Para Bento (2006), entretanto, ser transexual transcende a questão da aparência ou da mera aceitação genital. Segundo a autora, a maior luta travada por essas pessoas é pelo reconhecimento, por serem legitimamente vistos/as como eles/elas próprios/as se veem.

Dessa maneira, é necessário que gênero seja entendido aqui como performance cujas consequências são claramente punitivas (BUTLER, 2017), pois, ao se fugir da norma heterossexual compulsória e arbitrária, os/as estudantes trans estão sujeitos às punições. Esses mecanismos punitivos dão-se concretamente, como não poder usar o banheiro mais adequado a sua identidade de gênero, ser chamado/a pelo nome civil de nascimento, entre tantas outras estratégias, veladas ou não, que são estabelecidas por esse acordo cultural em que "homens" desempenham papéis sociais masculinos e "mulheres" desempenham aqueles relegados às mesmas:

Assim, o gênero é uma construção que normalmente oculta sua gênese; o acordo coletivo tácito de exercer, produzir e sustentar gêneros distintos e polarizados como ficções culturais é obscurecido pela credibilidade dessas produções - e pelas punições que penalizam a recusa a acreditar neles; a construção "obriga" nossa crença em sua necessidade e naturalidade (BUTLER, 2017, p. 241).

Logo, as possibilidades de fuga à heteronormatividade (o corpo trans) são punitivamente reguladas no discurso vigente que transita não só na escola, mas na sociedade como um todo. É esse discurso que, repetidamente, institui os papéis masculinos e femininos na sociedade, criando um

\footnotetext{
${ }^{4}$ A violência simbólica representa uma forma de violência invisível que se impõe numa relação do tipo subjugaçãosubmissão, cujo reconhecimento e a cumplicidade fazem dela uma violência silenciosa que se manifesta sutilmente nas relações sociais, resultando em dominação (ROSA, 2007, p. 40).
} 
regulador coletivo do que homens e mulheres, em um enfoque heteronormativo e cisgênero ${ }^{5}$, podem ou não fazer. Nessa perspectiva, "a produção do discurso é imediatamente controlada, selecionada, organizada e redistribuída por um certo número de procedimentos cujo papel é tutelar seus poderes e perigos" (FOUCAULT, 1981 apud FAIRCLOUGH, 2016, p. 79-80), visto que o discurso não só traduz as lutas de poder, mas também é o marco dessa luta e a razão dela. O poder, então, se utiliza dos sujeitos através das estratégias de disciplina e de confissão para se autorregular e se manter, caracterizando-se assim como "bio-poder” (FOUCAULT, 2014).

Assim, como "parte irredutível da vida social” (CHOULIARAKI; FAIRCLOUGH, 1999, p. 28, tradução nossa), o discurso oferece os meios pelos quais se pode verificar sua relação dialética com a própria sociedade, para que tanto as questões sociais (no caso do foco deste artigo, transfobia na escola) quanto as discursivas (mecanismos linguísticos utilizados pelos sujeitos transfóbicos) não sejam apenas objeto de análise, mas também motivação que engendre mudança social. Mudança essa que a ADC preconiza e incentiva, uma vez que tal corrente teórica, segundo Magalhães et al (2017, p. 149), "surge [...] como um imperativo ético e político em favor de pessoas e grupos em desvantagem".

Há, portanto, a necessidade de estudos cujo objetivo central seja desvendar as situações de discriminação e violência pelas quais alguns grupos sociais minoritários, como o de estudantes trans, passam na escola. Essas situações são mediadas pelo discurso como domínio da realidade social e por ele podem ser transformadas a partir do momento da conscientização dos sujeitos envolvidos em tais contextos de opressão, deslegitimação e retirada de direitos.

\section{NARRATIVAS TRANS NA ESCOLA: A GERAÇÃO DOS DADOS}

$\mathrm{O}$ estudo ocorreu em concomitância à geração de dados para a pesquisa intitulada "O DISCURSO LGBTIFÓBICO NA ESCOLA: Impactos sobre os corpos LGBTI+ de estudantes de quatro escolas públicas de Ensino Médio de Ceilândia - Distrito Federal”, no segundo semestre de 2018, fortemente provocada pelos os encontros do Projeto Portas Abertas ${ }^{6}$, realizado no Centro de Ensino Médio 02 de Ceilândia, durante o ano de 2017. A pesquisa aqui apresentada é tanto de ordem

\footnotetext{
${ }^{5}$ Refere-se a pessoa cuja sua identidade e expressão de gênero correspondem ao sexo biológico ao qual foram designadas quando nasceram.

${ }^{6}$ O Projeto Portas Abertas foi realizado em 2017 com o intuito de acolher estudantes LGBTI+ do Centro de Ensino Médio 02 de Ceilândia. Durante as atividades do projeto, os/as estudantes poderiam compartilhar suas histórias e discutir questões relacionadas à representatividade, direitos civis, orgulho e respeito à diversidade. $\mathrm{O}$ projeto foi também um provocador para a realização da dissertação de mestrado "O DISCURSO LGBTIFÓBICO NA ESCOLA: Impactos sobre os corpos LGBTI+ de estudantes de quatro escolas públicas de Ensino Médio de Ceilândia - Distrito Federal" de Leonardo da Cunha Mesquita Café e consta no PPP, Projeto Político-Pedagógico, da escola em que foi realizado.
} 
qualitativa, como interpretativista, sendo a Análise de Discurso Crítica adotada não só como teoria, mas também como método que busca "investigar criticamente a desigualdade social, porque ela manifesta-se, constitui-se e legitima-se no uso linguístico (ou no discurso) " (WODAK; MEYER, 2009 apud MAGALHÃES et al., 2017, p. 21).

É de ordem qualitativa, primeiramente, por transitar interdisciplinarmente por diferentes áreas do conhecimento - filosofia, linguística, sociologia - e por abordar temas transversais de interesse social - educação, sexualidade, cidadania. Em segundo lugar, é qualitativa por se apoiar em "um conjunto de práticas materiais e interpretativas que dão visibilidade ao mundo" (DENZIN; LINCOLN, 2006, p. 17), ou seja, práticas que possibilitam vislumbrar os contextos em seus aspectos qualitativos e não apenas quantitativos. Segundo Vieira e Resende (2016, p. 76), esse conjunto de práticas interpretativas possibilita "transformar aspectos do mundo em representações por meio das quais podemos entendê-lo, descrevê-lo e interpretá-lo" e, logo, suscitar as discussões necessárias a respeito dos sujeitos engajados na pesquisa. Portanto, as práticas interpretativas são fundamentais em uma pesquisa de ordem qualitativa, pois é fundamental que os colaboradores/as se expressem espontaneamente, falando e opinando sobre si e os outros (BAUER; GASKELL, 2008).

Dessa maneira, o estudo aqui efetivado é também interpretativista, já que se norteia por nossas concepções de mundo e nossas inclinações teórico-metodológicas, as quais podem ser situadas no arcabouço teórico da ADC. A adesão a essa determinada versão teórica justifica-se no objeto de estudo da própria pesquisa que trata dos impactos e demandas advindas da condição trans de estudantes de unidades de ensino públicas da periferia de Brasília.

Para a realização da pesquisa proposta aqui, foram gerados dados resultantes da colaboração de três estudantes trans: uma mulher e dois homens trans estudantes da rede pública de Ensino Médio, residentes de Ceilândia, cuja faixa etária variava de 16 a 18 anos. Tais estudantes estavam devidamente matriculados em duas escolas da Região Administrativa IX, Centro de Ensino Médio 02 e Centro Educacional 07, as quais foram escolhidas entre um grupo de quatro por apresentarem estudantes assumidamente trans, como já explicitado anteriormente.

Para a geração de dados da pesquisa, foram utilizados como procedimentos metodológicos notas de campo, entrevistas semiestruturadas e grupos focais. A escolha da metodologia foi motivada para que se pudesse obter maior qualidade nos dados gerados e para que o corpus resultante oferecesse uma visão ampla das opiniões dos/as colaboradores/as a respeito das peculiaridades da experiência pessoal como pessoa trans na escola.

Para os grupos focais e entrevistas semiestruturadas foram criados previamente tópicos-guia planejados "para dar conta dos fins e objetivos da pesquisa", como bem lembra Gaskell (2005, p. 66), os quais foram usados como norteadores flexíveis e sensíveis a mudanças documentadas. 
As notas de campo foram tomadas durante a observação de uma atividade realizada durante o Projeto Portas Abertas da qual participavam dois estudantes trans. Essa ferramenta metodológica promove acesso às práticas sociais durante um determinado evento social e esclarece dados importantes, muitas vezes, não evidentes aos outros procedimentos, como, por exemplo, elementos relacionados à comunicação não-verbal ou à percepção do pesquisador (BAUER; GASKELL, 2008).

Durante a realização dos grupos focais e das entrevistas, os/as colaboradores/as trans se encontravam em ambiente reservado dentro da própria escola (biblioteca, centro cultural ou sala de vídeo) e em horário letivo para que fosse garantida sua segurança, bem como para assegurar melhor qualidade de áudio aos dados capturados via gravador. Os dados selecionados relatam as experiências dos/as entrevistados/as, vividas no ambiente escolar, e versam sobre os impactos da transfobia nesse contexto e sobre as demandas e estratégias de enfrentamento adotadas pelos/as participantes.

Por fim, a geração de dados ocorreu entre agosto a dezembro de 2018, totalizando três entrevistas individuais (12 a 20 minutos cada em média) e dois grupos focais (30 minutos cada em média), além das notas de campo realizadas durante o período das atividades do Projeto Portas Abertas no decorrer do ano de 2017 (oito encontros mensais de 1h30min cada).

\section{ANÁLISE}

Para a análise dos dados deste estudo, como foi dito anteriormente, utilizou-se a Análise de Discurso Crítica não só como teoria, mas também como método, através das contribuições epistemológicas de Fairclough (2016), Magalhães et al (2017), além de Ramalho e Resende (2016, 2017). Nessa linha, a interdisciplinaridade teórico-metodológica recorre também aos conceitos de identidade de gênero (BUTLER, 2017), sexualidade e poder (FOUCAULT, 2014; 2018) e de sexualidade na escola (MOITA LOPES, 2008; LOURO, 2014; 2016) discutidos na seção teórica desse estudo.

Nessa integração, os dados gerados são analisados tanto linguisticamente, por causa dos seus efeitos sociais, quanto discursivamente, por se considerar outras semioses não tão explícitas, como a linguagem não-verbal, que podem emergir nas narrativas dos/as colaboradores/as. As relações de poder, dominação e as estratégias ideológicas são tratadas também nessa análise cujos dados estão organizados em três tópicos:

- A demanda por pertencimento no contexto escolar;

- Impactos sobre o corpo trans: Violência física e emocional / Anulação do ser;

- Estratégias de enfrentamento à transfobia na escola: Embate / Conformação e resignação. 
Os dados gerados apontam uma realidade em que o tema da sexualidade, mesmo que aparente em vários contextos sociais, ainda parece ser um tabu quando voltamos nossa atenção à escola e analisamos as práticas discursivas dos sujeitos nela presentes. O corpo, ali, é apagado do seu desejo e de suas peculiaridades para que apenas a cognição, a "mente", tenha status de prestígio no ambiente escolar. Todavia, "esse processo de esquecer o corpo naturaliza ideais corpóreos de raça como branquitude, de gênero como masculinidade e de sexualidade como heterossexualidade" (MOITA LOPES, 2008, p. 126), denotando não um simples apagamento dos corpos, mas sim o apagamento de determinados corpos: daqueles que fogem da "instância da regra" do poder:

O poder seria, essencialmente, aquilo que dita a lei, no que diz respeito ao sexo. $\mathrm{O}$ que significa, em primeiro lugar, que o sexo fica reduzido, por ele, a regime binário: lícito e ilícito, permitido e proibido. Em seguida, que o poder prescreve ao sexo uma "ordem" que funciona, ao mesmo tempo, como forma de inteligibilidade: o sexo se decifra a partir de sua relação com a lei [...] o domínio do poder sobre o sexo seria efetuado através da linguagem, ou melhor, por um ato de discurso que criaria, pelo próprio fato de enunciar, um estado de direito (FOUCAULT, 2018, p. 81).

Foucault (2018) nos apresenta o poder em sua forma normativa, prescrevendo o que pode ou não ser realizado em termos de sexualidade: os corpos lícitos e os ilícitos. Sua contribuição corroborou com a ideia de apagamento sexual na escola trazida por Moita Lopes (2008) e acrescenta ainda o caráter discursivo da materialização desse poder pela linguagem em um ciclo de dominação sobre o sexo.

Para Foucault (2018), a forma mais "pura” dessa relação de poder estaria configurada na “função do legislador", isto é, daquele que dita o que pode ou não ser dito, o que pode ou não ser considerado um corpo legítimo. A ilustração dessa função foucaultiana sobre o outro é evidenciada através das narrativas de " $\mathrm{D}$ ", aluna trans, que relata como essas formas de poder na escola legitimam as condutas de quem tem prestigio ou não nesse contexto:

\section{Excerto 1 - A demanda por pertencimento no contexto escolar}

\begin{tabular}{|l|l|l|}
\hline \multirow{4}{*}{ Pesquisador } & $\mathbf{1}$ & O que mais te incomoda na sua rotina aqui na escola? \\
\hline \multirow{3}{*}{ D } & $\mathbf{2}$ & Seria fácil se fosse pouca coisa, né? Assim, não é que eu odeie a escola...eu \\
\cline { 2 - 4 } & $\mathbf{3}$ & gosto, gosto bastante..., mas muita coisa me dá vontade de sumir, saca? De \\
\cline { 2 - 3 } & $\mathbf{4}$ & desaparecer...coisas que ficam me lembrando do quanto eu odeio esse \\
\cline { 2 - 3 } & $\mathbf{5}$ & corpo... \\
\hline Pesquisador & $\mathbf{6}$ & Mas que coisas são essas? Por que elas te fazem se sentir tão mal? \\
\hline & $\mathbf{7}$ & Imagina só você ter medo de ir ao banheiro! Ás vezes fico segurando pra ir \\
\cline { 2 - 3 } & $\mathbf{8}$ & em casa a manhã toda... é um conflito, sabe? Quero ir ao banheiro das \\
\hline
\end{tabular}




\begin{tabular}{|l|l|l|}
\hline \multirow{4}{*}{ D } & $\mathbf{9}$ & meninas, eu pertenço aquele lugar..., mas daí tem umas gurias que leva de \\
\cline { 2 - 3 } & $\mathbf{1 0}$ & boa, já outras me olham como se eu fosse uma aberração. Tem também os \\
\cline { 2 - 3 } & $\mathbf{1 1}$ & idiotas dos meninos...eles ficam zoando, falando pra eu ir pro banheiro deles \\
\cline { 2 - 3 } & $\mathbf{1 2}$ & que é meu lugar. Não vou mesmo, prefiro fazer nas calças...um dia ouvi um \\
\cline { 2 - 3 } & $\mathbf{1 3}$ & garoto falando que se eu entrasse lá ia ver como me endireitava na hora... \\
\hline
\end{tabular}

"D” inicia seu relato pelo reforço da oração sobre sua rotina na escola que é muito difícil e complexa em "seria fácil se fosse pouca coisa, né? ” (1.2), fala enfatizada pelo uso dos verbos “sumir” (1.3) e "desparecer” (1.4) em uma clara referência à deslegitimação pela qual seu corpo trans passa diariamente. Tais verbos ilustram a força que o discurso tem sobre as relações entre as pessoas e sobre os sistemas de crença que esses mesmos discursos ajudam a criar. Por outro lado, ela tenta amenizar a aparência opressora da escola contornando afirmativas e utilizando negativas como "não é que eu odeie a escola" (1.2), além da repetição lexical de "gosto" (1.3), o que reforça sua tentativa de convivência no ambiente junto aos demais estudantes. No entanto, é alarmante como as práticas discursivas relatadas fazem com que a colaboradora construa uma imagem ainda mais negativa em relação a si mesma, especialmente pelo uso do verbo “odeio" (1.4) conjugado no presente do indicativo, confirmando uma situação perenal de carga semântica tão forte. Além disso, o uso dos pronomes também marca muito taxativamente a rejeição e a exclusão a que remete seu corpo. $\mathrm{O}$ pronome indefinido "quanto" (1.4) reforça o grau elevado dessa rejeição Outros pronomes, como “esse" (1.4), para qualificar "corpo" (1.5), e "banheiro deles" (1.11), levam para o âmbito do tu e do eles, no discurso, as marcas de não pertencimento. Para Benveniste (1995, p. 286),

é na linguagem e pela linguagem que o homem se constitui como sujeito. [...]. Eu não emprego $e u$ a não ser dirigindo-me a alguém, que será na minha alocução um $t u$. Essa condição de diálogo é que é constitutiva da pessoa, pois implica uma reciprocidade. [...]. Por isso, eu propõe outra pessoa, aquela que, sendo embora exterior a mim, torna-se meu eco - ao qual eu digo $t u$ e que me diz $t u$. O uso do demonstrativo na segunda pessoa - e não este corpo, na primeira pessoa - afasta para o âmbito do "eco", e não do "sujeito" o pertencimento do corpo rejeitado.

Além disso, a terceira pessoa - ou não pessoa”, segundo Benveniste (1995) -, em “banheiro deles" (1.11), confirma o sentimento de não pertencimento ao lugar, que anteriormente já ficava implicado na assunção explícita de "eu pertenço àquele lugar" (1.9), a respeito do banheiro das meninas. Através das marcas localizadas das estruturas linguísticas que usa em seu relato, "D” se coloca em lugar específico em que se revela a deslegitimação do seu corpo - tanto por ela quanto pelos outros. 
Ainda, acerca desse fragmento, se aqui voltarmos a Foucault (2018): Quem são os legisladores que fazem com que uma ida ao banheiro se torne um perigo iminente? Quem são os responsáveis por colocarem " $D$ " no espaço do não-pertencimento? Seria leviano acreditar que os sujeitos criem por si sós as representações de corpos legítimos ou não. É mais prudente pensar nos efeitos construtivos do discurso:

O discurso contribui, em primeiro lugar, para a construção do que variavelmente é referido como 'identidades sociais' e posições de sujeito' para os 'sujeitos' sociais e os tipos de 'eu' [...] Segundo, o discurso contribui para construir as relações sociais entre as pessoas. E, terceiro, o discurso contribui para a construção de sistemas de crença (FAIRCLOUGH, 2016, p. 95).

Se o discurso contribui para a construção das identidades sociais, relações sociais entre as pessoas e para a construção de sistemas de crenças, fica evidente que há algo a mais que orienta determinados discursos a naturalizar determinadas práticas e prestigiar determinados sujeitos. A isso chamamos de ideologia cujo caráter, neste estudo, é cisheteronormativo e, por isso, legitima os sugeridos ( "como se fosse uma aberração" - 1.10) e os ditos ("me endireitava na hora" - 1.13) que não só discriminam, mas, sobretudo, ameaçam a existência de quem foge à hegemonia cisheterossexual:

A produção de seres abjetos e poluentes (gays, lésbicas, travestis, transexuais, e todos os seres que fogem à norma de gênero) e a desumanização do humano são fundamentais para garantir a reprodução da heteronormatividade. A escola é uma das instituições centrais nesse projeto (BENTO, 2011, p. 554).

Além disso, a entrevista de " $\mathrm{D}$ " evidencia uma urgente demanda por pertencimento que tem sido negligenciada. Ela própria deixa essa luta clara quando diz que "quero ir ao banheiro das meninas, eu pertenço àquele lugar" (1.8 e 1.9). Lembremos que, na escola, interagimos e tecemos relações importantes para a formação do sujeito que não estão sendo atendidas quando pensamos nos/nas estudantes que subvertem a norma de padrão sexual esperada socialmente, levando pessoas trans, como "A", a sofrer violências físicas, emocionais e simbólicas dentro da própria instituição:

\section{Excerto 2 - Impactos sobre o corpo trans: violência física e emocional ${ }^{7}$}

\begin{tabular}{|l|c|l|}
\hline Pesquisador & $\mathbf{1}$ & As imagens mostram pessoas sofrendo violências de várias maneiras. Vocês já se \\
\cline { 2 - 3 } & $\mathbf{2}$ & sentiram assim na escola? Algo parecido já aconteceu a vocês? \\
\hline A & $\mathbf{3}$ & Ah... ruim falar isso... mas me machucaram lá, por isso fui transferido...não quero \\
\cline { 2 - 3 } & $\mathbf{4}$ & lembrar disso...me senti muito desprotegido e frágil...foi foda... fico bolado até hoje \\
\cline { 2 - 3 } & $\mathbf{5}$ & com essa parada sinistra... \\
\hline
\end{tabular}

\footnotetext{
${ }^{7}$ Apesar da pergunta não parecer formalmente aberta nesse relato gerado em grupo focal, ela tampouco indica a transfobia como possível resposta, pois "as imagens mostram pessoas sofrendo violências de várias maneiras".
} 
A violência simbólica relatada por "D" confirma-se na resposta de "A". No excerto, ele a relata, demonstrando muito mais fisicamente do que através de sua fala. Ao relacionar as imagens à violência, o rapaz trans recolhe-se na cadeira e mantém o olhar para baixo. Hesita ao falar, em um evidente desconforto, levando as mãos ao pescoço onde há marcas físicas da violência a que foi submetido $^{8}$. Ao utilizar os adjetivos "desprotegido" (1.4) e "frágil" (1.4), nota-se como "A" estava suscetível às práticas que desconsideram sua identidade e não reconhecem sua existência dentro da escola.

Além disso, é importante notar como o uso do gênero gramatical masculino em "transferido" (1.3), "desprotegido" e "bolado" (1.4) reforça sua consciência de identidade de gênero trans masculina, mesmo que essa não seja respeitada pelos demais sujeitos na escola. Tal desrespeito se caracteriza como uma violência física e simbólica que pode trazer consequências emocionais diversas para as pessoas trans. Ainda sobre como a transfobia impacta a existência trans no contexto escolar, ele relata outro episódio:

Excerto 3 - Impactos sobre o corpo trans: anulação do ser

\begin{tabular}{|l|l|l|}
\hline A & $\mathbf{1}$ & Uma vez eu passei no corredor e aí gritaram pra eu parar de querer ser homem porque \\
\cline { 2 - 4 } & $\mathbf{2}$ & eu nunca vou ser HOMEM de verdade... \\
\cline { 2 - 4 } & $\mathbf{3}$ & Quem eles são pra dizer quem eu sou? Só eu que sei como é dolorido acordar todo dia \\
\cline { 2 - 4 } & $\mathbf{4}$ & me sentindo homem e olhando pra um corpo desse jeito aqui... \\
\hline
\end{tabular}

Segundo Silva e Magalhães (2017, p. 52), "tudo o mais que não é legitimado pelo discurso hegemônico é dele diferenciado e expurgado" e pode, assim, levar os sujeitos pertencentes ao gênero hegemônico a determinar quem é ou não é homem, anulando a existência de "A". Apesar disso, o aluno reconhece seu local de fala quando questiona "quem eles são pra dizer quem eu sou?" ou ao usar a afirmação "só eu sei como é dolorido (...)” (1.3), além de enfatizar o sofrimento oriundo da não-correspondência entre sua identidade de gênero e a atribuição biológica nas expressões adverbiais "todo dia" (1.3) e "aqui" (1.4). Cabe ressaltar também que "Ser HOMEM de verdade" (1.2) é uma norma estabelecida pelo "regime da heterossexualidade" que "atua para circunscrever e contornar a 'materialidade' do sexo", como afirma Butler (1993, p. 15) dentro de um paradigma de uniformidade sexual que não existe dada à própria presença de pessoas trans em nossa sociedade. Ao mesmo tempo em que não aceita ser definido pelos outros, "A" advoga para si o direito de ser ele a decidir sobre seu lugar na sociedade - mesmo que reconheça sofrimento nessa decisão.

\footnotetext{
${ }^{8}$ Outras semioses discursivas registradas em nota de campo do pesquisador durante grupo focal com os/as estudantes trans participantes da pesquisa.
} 
Então, frente aos impactos imputados às pessoas trans expostos pelas falas discutidas, como enfrentar a hegemonia sexual vigente nas práticas discursivas e sociais presentes nos textos dos diversos sujeitos do contexto escolar? Como não se calar frente às constantes negativas que desconsideram a existência trans? "F", outro aluno colaborador trans, demonstra sua persistência quanto ao reconhecimento de sua identidade no seguinte relato:

Excerto 4 - Estratégias de enfrentamento à transfobia na escola: embate

\begin{tabular}{|l|c|l|}
\hline Pesquisador & $\mathbf{1}$ & Como você lida com episódios transfóbicos na escola? \\
\hline F & $\mathbf{2}$ & Pois é, difícil, mas a gente não desiste. Tem aquele professor, sabe? Sempre me chama \\
\cline { 2 - 4 } & $\mathbf{3}$ & pelo nome civil... já falei com ele milhares de vezes, mas ele sempre me chama pelo \\
\cline { 2 - 4 } & $\mathbf{4}$ & nome feminino... ah e também fica dizendo “cadê aquela menina?" ou "ah, foi \\
\cline { 2 - 4 } & $\mathbf{5}$ & mal...mas você entende, né? ”... Fora as vezes que se refere a mim com “ela”. \\
\cline { 2 - 4 } & $\mathbf{6}$ & Mas ele se deu mal agora...tô indo na direção toda vez que ele fica com essas gracinhas \\
\cline { 2 - 4 } & $\mathbf{7}$ & e já avisei que vou chamar meus pais aqui... quero ver se ele não vai parar... \\
\hline
\end{tabular}

O professor, no relato de "F", parece não compreender que as identidades não são fixas ou constantes, mas que podem ser contraditórias e cambiantes (HALL, 2006), como no caso de seu aluno trans. Mesmo sendo advertido "milhares de vezes" (1.3), o professor persiste em tratar "F" como mulher ( "cadê aquela menina? " e "ela" - 1.4 e 1.5), usando seu registro civil (me chama pelo nome feminino" - 1.3), o que caracteriza aqui uma relação de poder desigual na qual, claramente, percebese que "a afirmação da identidade e da diferença no discurso traduzem conflitos de poder entre grupos assimetricamente situados" (RESENDE; RAMALHO, 2017, p. 77).

O relato ressalta a importância da nomeação nas práticas discursivas: o primeiro "local" de identificação de algo ou de alguém é conferido pela designação do nome. Daí a grande relevância do reconhecimento do nome social para as minorias trans, pois ao nomear alguém, se legitima a presença desse sujeito em relação aos outros e se estabelece um marco presencial inicial pela luta e resistência frente à transfobia.

Nesse embate, apesar da posição assimétrica inferior, "F" recorre às instâncias regulatórias ("tô indo na direção" e "vou chamar meus pais aqui"- 1.6 e 1.7) para que suas demandas sejam atendidas, caracterizando sua iniciativa como uma estratégia de enfrentamento muito necessária para o que Bento (2014, p. 179) afirma ser uma disputa entre as várias “visões e projetos de humanidade" pela qual as pessoas trans lutam afim de que seus corpos sejam, também, humanizados.

Diferentemente, outras estratégias utilizadas por estudantes trans acabam sendo de conformação ou de resignação quanto à transfobia, provavelmente por esta ser "consentida e ensinada 
na escola” e expressa “pelo desprezo, pelo afastamento, pela imposição do ridículo" (LOURO, 2016, p. 29) como pode ser percebido em um último relato de " $D$ ":

Excerto 5 - Estratégias de enfrentamento à transfobia na escola: conformação e resignação

\begin{tabular}{|l|c|l|}
\hline Pesquisador & $\mathbf{1}$ & E você lida como com os episódios de transfobia aqui na sua escola? \\
\hline D & $\mathbf{2}$ & Aiaiai, então [...] sabia que eu já fui bem atrevida? Brigava mesmo e fazia o que fosse \\
\cline { 2 - 4 } & $\mathbf{3}$ & necessário para defender meus direitos, mas a gente cansa também... \\
\cline { 2 - 3 } & $\mathbf{4}$ & Tem horas que ouço uma piadinha e finjo que não é comigo. Deixo pra lá, saca? \\
\cline { 2 - 3 } & $\mathbf{5}$ & Acho que estou me poupando para coisas mais graves, meu couro já ficou duro... \\
\hline & $\mathbf{6}$ & nem perco tempo com conversinha ou olhar torto, apesar de me machucarem ainda. \\
\cline { 2 - 3 } & $\mathbf{7}$ & Vou vivendo que uma hora melhora, né? \\
\hline
\end{tabular}

"D”, aluna trans cuja fala iniciou a seção de discussão, começa este relato com uma pausa muito simbólica que vem seguida de uma declaração interessante ( "sabia que eu já fui bem atrevida" - 1.2) sobre como ela costumava ser. Aqui não se espera uma resposta do pesquisador, mas sim sua atenção para o que será dito. Nota-se na narrativa que " $D$ " sempre foi combativa ("Brigava mesmo" - 1.2) e que lutava por seus direitos no espaço escolar. Entretanto, a aluna termina esse período com uma afirmação importante para essa análise: “mas a gente cansa...” (1.3). Essa afirmação talvez demonstre o quão extenuante seja estar em um ambiente onde o seu corpo é alvo do discurso da deslegitimação, onde o seu corpo é negado e, por conseguinte, a sua existência é anulada. Segundo Foucault (2018), o simples fato de falar sobre o sexo, que é fadado à proibição, "possui como que um ar de transgressão deliberada". Imagine-se, então, quando não é sequer necessário falar do sexo porque as marcas de sua diferença estão abertamente expressas para que sejam subjugadas e discriminadas.

"D" continua e mostra suas estratégias de enfrentamento já menos combativas, mas de autopreservação que ficam claras quando diz "finjo que não é comigo" (1.4). A aluna parece buscar aprovação ao se mostrar conformada com a situação em “Deixo pra lá, saca? " (1.4), como se precisasse ouvir algo que a confortasse frente ao que vive. A estudante traz também alguns outros indícios de sua resignação perante as vicissitudes de sua trajetória trans na escola. "D" tenta se convencer de que sua resignação seja passageira ( "Acho que estou me poupando para coisas mais graves" - 1.5), apesar de usar o verbo "achar" cuja carga semântica orienta para a mitigação da informação.

Outro indicador dessa conformação é a explicação de que seu “couro já ficou duro" (1.5), em uma alusão aos percalços enfrentados devido à transfobia a que é submetida. Transfobia essa que se fundamenta nos discursos cisheteronormativos privilegiados que têm início logo após o nascimento 
quando "a afirmação é um menino" ou " é uma menina" inaugura um processo de masculinização ou feminilização dos sujeitos" que os acompanhará por toda a vida, cobrando-lhes um comprometimento quanto às normas que regulam sua cultura, a fim de que se qualifiquem como corpos legítimos, como corpos que importam (BUTLER, 1999 apud LOURO, 2015, p. 16).

Dessa forma, "D” e outros/as estudantes trans transgredem o processo de masculinização/feminilização baseado nos discursos de heterogeneidade e cisgeneridade ${ }^{9}$ como única via de legitimidade dos corpos. Por isso mesmo, "D", ainda que tente negar ( "nem perco tempo com conversinha ou olhar torto” - 1.6), sente-se ferida pelas práticas sociais escolares nas quais está envolvida ( "apesar de me machucarem ainda"-1.6). Ao final de sua narrativa, é triste constatar que "D” siga apenas “vivendo" (1.7) à espera de que "uma hora” (1.7) as coisas melhorem e ela possa existir legitimamente onde quer que esteja.

Desta forma, o discurso na escola, moldado à luz da ideologia cisheteronormativa é transfóbico, pautando-se por uma dicotomia baseada na cristalização do binômio masculino $v s$ feminino, a qual deslegitima as identidades de gênero que não se reconhecem na atribuição biológica do sexo (BRUNS; PINTO, 2003). Tal discurso privilegia a concepção heteronormativa e desconsidera a homoafetividade, o que se percebe em relações interacionais assimétricas ou não. $\mathrm{O}$ discurso desempenha papel decisivo na reprodução da dominação que, por conseguinte, gera desigualdade social (transfobia, no caso deste artigo) pelo uso abusivo do discurso nas relações de poder (VAN DIJK, 2017).

O abuso discursivo a que se refere o parágrafo anterior pode ser notado pelo que é relatado nos textos dos/das estudantes, bem como através da observação dos contextos em que esses textos são produzidos. Tais textos concretizam a diferença de acesso que determinados grupos têm e de que maneira seus dizeres pesam sobre corpos específicos, especialmente dos alunos e alunas transexuais que divergem da norma heterossexual, confirmando a tese de van Dijk (2017) sobre a relação assimétrica de acessolcontrole discursivo e dominação, uma vez que "os grupos mais poderosos e seus membros controlam ou têm acesso a uma gama cada vez mais ampla e variada de papéis, gêneros, oportunidades e estilos de discurso" e acabam determinando não só sobre o que se fala, mas também quem fala (VAN DIJK, 2017, p. 44).

\footnotetext{
${ }^{9}$ Refere-se a condição de ser cisgênero, isto é, de ter identificação e expressão de gênero consoantes às que lhes foram atribuídas no nascimento. É a condição oposta à transgeneridade. O termo nasce da necessidade de expor os privilégios da condição cisgênera em oposição à transgênera, pois "a cisgeneridade como norma acarreta na desumanização de pessoas trans, uma vez que elas não seguem a coerência desta norma e, por isso, não têm os seus nomes sociais e identidades respeitadas, são excluídas ou marginalizadas em espaços de convívio social, enfrentam dificuldades em relação ao mercado de trabalho, ao acesso à saúde, em relacionamentos afetivos, e até mesmo em níveis humanos básicos e fisiológicos, como no livre acesso e segurança no uso de banheiros públicos" (LEONARDO; ATHAYDE; POCAHY, 2014, p. 6).
} 


\section{CONSIDERAÇÕES FINAIS}

A análise dos textos indica que a transfobia é uma espécie de apartheid sexual (MCLAREN, 1995) que segrega estudantes trans dentro da própria escola "por meio da limitação da participação no espaço social" (SILVA et al., 2015, p. 369) e através de discursos baseados em uma hegemonia sexual cisheteronormativa, impactando de maneira desconstrutiva sobre a sexualidade e sobre o sentimento de pertencimento dos/das estudantes trans.

Foi, por conseguinte, revelado o quanto tais mecanismos discursivos, linguísticos ou não, afetam a autoestima de alunos/as trans por negarem sua existência por meio do não-atendimento de suas demandas de convivência harmônica, como usar o banheiro que melhor atenda sua identidade de gênero, e de reconhecimento identitário, como ser tratado/a pelo pronome que reflita seu corpo trans ou pelo nome social.

Apesar desse cenário de exclusão, os dados sugerem que estratégias de enfrentamento são possíveis, mesmo ainda persistindo a atmosfera de resignação e conformação frente à discriminação presente nas práticas discursivas dos diversos sujeitos escolares. Daí a importância do envolvimento dos sujeitos integrantes da rotina escolar (gestão, setor administrativo, terceirizados/as, docentes e discentes), da prática do estudo e da discussão constante nas coletivas pedagógicas de professores/as e da promoção de palestras, mostras e saídas de campo que façam com que todos/as os/as estudantes, trans ou não, possam vivenciar a prerrogativa do respeito à diversidade.

Acredita-se que o estudo apresentado se constitui como uma iniciativa para que se reconsidere a visão de descorporificação vigente na sociedade e, por consequência, na escola. Crê-se, também, que o estudo mostra alguns tabus relacionados à homogeneidade sexual que precisam ser revistos e discutidos de maneira mais efetiva por docentes e demais sujeitos interagentes da escola.

Por fim, outros estudos qualitativos que discutam e analisem o papel da escola na deslegitimação dos corpos trans e que se aprofundem em outras narrativas desse grupo minoritário são fundamentais e urgentes para que a escola passe de um agente de reprodução do discurso que legitima e privilegia a cisheteronormatividade a um lugar onde as diferenças sejam acolhidas e o respeito seja o mote que norteia suas atividades. Dessa maneira, tais estudos futuros poderão nos ajudar a entender os porquês de alguns corpos serem legitimados enquanto outros não o são (BUTLER, 1993) e, consequentemente, poderão ativar mudanças sociais, dando oportunidade para que todos/as tenham direito efetivo à cidadania e que as vozes trans sejam realmente ouvidas, além de reconhecidas.

\section{REFERÊNCIAS}


AKOPOULOU, A. G. Small stories, interaction and identities. Amsterdam and Philadelphia: John Benjamin Publishing Company, 2007.

BAUER, M. W.; GASKELL, G. Pesquisa qualitativa com texto, imagem e som: um manual prático. Petrópolis, RJ: Vozes, 2008.

BENTO, B. A (re)invenção do corpo, gênero e sexualidade na experiência transexual. Rio de Janeiro: Garamond/Clam, 2006.

BENTO, B. Na escola se aprende que a diferença faz diferença. Estudos Feministas, Florianópolis, v. 19, n. 2, p. 548-558, 2011.

BENTO, B. Nome social para pessoas trans: cidadania precária e gambiarra legal. Contemporânea, Santa Catarina, v. 4, n. 1, p. 162-185, 2014.

BENVENISTE, É. Da subjetividade na linguagem. In: BENVENISTE, É. Problemas de Linguística Geral I. Campinas, SP: Pontes, 1995, p. 284-293.

BRUNS, M. A. de T.; PINTO, M. J. C. Vivência Transexual: o corpo desvela seu drama. Campinas, SP: Editora Átomo; 2003.

BUTLER, J. P. Bodies that matter, on the discursive limits of sex. New York: Roudedge, 1993.

BUTLER, J. P. Problemas de gênero: feminismo e subversão da identidade. Tradução: Renato Aguiar. Rio de Janeiro: Civilização Brasileira, 2017.

CHOULIARAKI, L.; FAIRCLOUGH, N. Discourse in Late Modernity. Edinburgh: Edinburgh University Press, 1999;

DENZIN, N. K.; LINCOLN, Y. S. A disciplina e a prática da pesquisa qualitativa. In: DENZIN, N. K.; LINCOLN, Y. S. (org.). O planejamento da pesquisa qualitativa: teorias e abordagens. Porto Alegre: Artmed; Boojman, 2006, p. 15-41.

FAIRCLOUGH, N. Discurso e mudança social. Brasília: Editora Universidade de Brasília, 2016.

FOUCAULT, M. Vigiar e punir: nascimento da prisão. Petrópolis, RJ: Vozes, 2014;

FOUCAULT, M. História da Sexualidade 1: A vontade de saber. Tradução Maria Thereza da Costa Albuquerque e J. A. Guilhon Albuquerque. Rio de Janeiro /São Paulo: Paz e Terra, 2018.

GNERRE, M. Linguagem, escrita e poder. São Paulo: Editora Martins Pontes, 1999.

HALL, S. A identidade cultural na pós-modernidade. Tradução de Tomaz Tadeu da Silva e Guacira Lopes Louro. Rio de Janeiro: DP\&A, 2006.

LEONARDO, R. C; ATHAYDE, T; POCAHY, F. A. O Conceito de cisgeneridade e a produção de deslocamentos nas políticas feministas contemporâneas. In: SEMINÁRIO INTERNACIONAL ENLAÇANDO SEXUALIDADES - 10 anos, 5., 2014. Anais [...]. p. 1-10, 2014. Disponível em https://www.editorarealize.com.br/revistas/enlacando/trabalhos/TRABALHO_EV072_MD1_SA2_I D903_17072017205519.pdf. Acesso em 09/09/2019. 
LOURO, G. L. Gênero, sexualidade e educação: uma perspectiva pós-estruturalista. Petrópolis: Editora Vozes, 2014.

LOURO, G. L. Um corpo estranho: ensaios sobre sexualidade e teoria queer. Belo Horizonte: Autêntica, 2015.

LOURO, G. L. (org.). O corpo educado: pedagogias da sexualidade. Belo Horizonte: Autêntica, 2016.

MAGALHÃES, I.; MARTINS, R.; RESENDE, V. de M Análise de Discurso Crítica: Um método de pesquisa qualitativa. Brasília: Editora Universidade de Brasília, 2017.

MCLAREN, P. A vida nas escolas: uma introdução à pedagogia crítica nos fundamentos da educação. Tradução: Lúcia Pellanda Zimmer. Porto Alegre: Artes Médicas, 1997.

MELO, I. F. (org.). Introdução aos estudos críticos do discurso: Teoria e prática. Campinas, SP: Pontes Editores, 2012;

MOITA LOPES, L. P da. Sexualidades em sala de aula: discurso, desejo e teoria queer. In: MOREIRA, Antônio Flávio; CANDAU, Vera Maria. (org.). Multiculturalismo: diferenças culturais e práticas pedagógicas. Petrópolis, RJ: Vozes, 2008, p. 125-148.

RESENDE, V. de M.; RAMALHO, V. Análise de discurso crítica. São Paulo: Contexto, 2017.

ROSA, A. R. (O) Braço forte, (a) mão amiga: um estudo sobre a dominação masculina e violência simbólica em uma organização militar. Lavras: UFLA, 2007.

SILVA, A. P. R.; MAGALHÃES, I. Transformações Discursivas das Identidades de Gênero na Mídia. Cadernos de Linguagem e Sociedade, Brasília, v. 18, n. 2, p. 45-63, 2017.

SILVA, R; BEZERRA, W C; QUEIROZ, S. B. Os impactos das identidades transgênero na sociabilidade de travestis e mulheres transexuais. Revista Terapia Ocupacional, São Paulo, v. 26, n. 3, p. 364-372, 2015.

SOUZA, L. A. de O. "Meu corpo, minhas regras": representações e identidades de gênero nos discursos de ativistas (trans)feministas. 2018. 307 f., il. Tese (Doutorado em Linguística) Universidade de Brasília: Brasília, 2018.

THOMPSON, John B. Ideologia e cultura moderna: teoria social crítica na era dos meios de comunicação em massa. Tradução: Grupo de Estudos sobre Ideologia, comunicação e representações sociais da pós-graduação do Instituto de Psicologia da PUCRS. Petrópolis, RJ: Vozes, 2011.

VAN DIJK, T. A. Discurso e poder. São Paulo: Contexto, 2017.

VIEIRA, V.; RESENDE, V. de M. Análise de discurso (para a) crítica: O texto como material de pesquisa. Campinas, SP: Pontes Editores, 2016. 